\title{
Corrigendum: Whole Genome Sequencing: Bridging One-Health Surveillance of Foodborne Diseases
}

OPEN ACCESS

Approved by:

Frontiers Editorial Office

Frontiers Media SA, Switzerland

${ }^{*}$ Correspondence:

Peter Gerner-Smidt

plg5@cdc.gov

Specialty section

This article was submitted to Infectious Diseases - Surveillance,

Prevention and Treatment,

a section of the journal

Frontiers in Public Health

Received: 02 October 2019 Accepted: 18 November 2019 Published: 06 December 2019

Citation:

Gerner-Smidt P, Besser J, Concepción-Acevedo J, Folster JP, Huffman J, Joseph LA, Kucerova Z, Nichols MC, Schwensohn CA and Tolar B (2019) Corrigendum: Whole

Genome Sequencing: Bridging One-Health Surveillance of Foodborne Diseases. Front. Public Health 7:365.

doi: 10.3389/fpubh.2019.00365

\section{Peter Gerner-Smidt ${ }^{1 *}$, John Besser ${ }^{1}$, Jeniffer Concepción-Acevedo ${ }^{1}$, Jason P. Folster ${ }^{1}$, Jasmine Huffman ${ }^{1}$, Lavin A. Joseph ${ }^{1}$, Zuzana Kucerova ${ }^{1}$, Megin C. Nichols ${ }^{2}$, Colin A. Schwensohn ${ }^{2}$ and Beth Tolar ${ }^{1}$ \\ ${ }^{1}$ The Enteric Diseases Laboratory Branch, Centers for Disease Control and Prevention, Atlanta, GA, United States, ${ }^{2}$ The Outbreak Response and Prevention Branch, Centers for Disease Control and Prevention, Atlanta, GA, United States}

Keywords: whole genome sequencing (WGS), outbreak, one health, zoonotic, food, environment, animals, investigation

\section{A Corrigendum on}

Whole Genome Sequencing: Bridging One-Health Surveillance of Foodborne Diseases by Gerner-Smidt, P., Besser, J., Concepción-Acevedo, J., Folster, J. P., Huffman, J., Joseph, L. A., et al. (2019). Front. Public Health 7:172. doi: 10.3389/fpubh.2019.00172

In the original article, there was a mistake in Figure $\mathbf{1}$ and Figure $\mathbf{2}$ as published. The graphics used are different than those originally submitted. The corrected Figure 1 and Figure 2 appear below.

The authors apologize for this error and state that this does not change the scientific conclusions of the article in any way. The original article has been updated.

Copyright (C) 2019 Gerner-Smidt, Besser, Concepción-Acevedo, Folster, Huffman, Joseph, Kucerova, Nichols, Schwensohn and Tolar. This is an open-access article distributed under the terms of the Creative Commons Attribution License (CC BY). The use, distribution or reproduction in other forums is permitted, provided the original author(s) and the copyright owner(s) are credited and that the original publication in this journal is cited, in accordance with accepted academic practice. No use, distribution or reproduction is permitted which does not comply with these terms. 


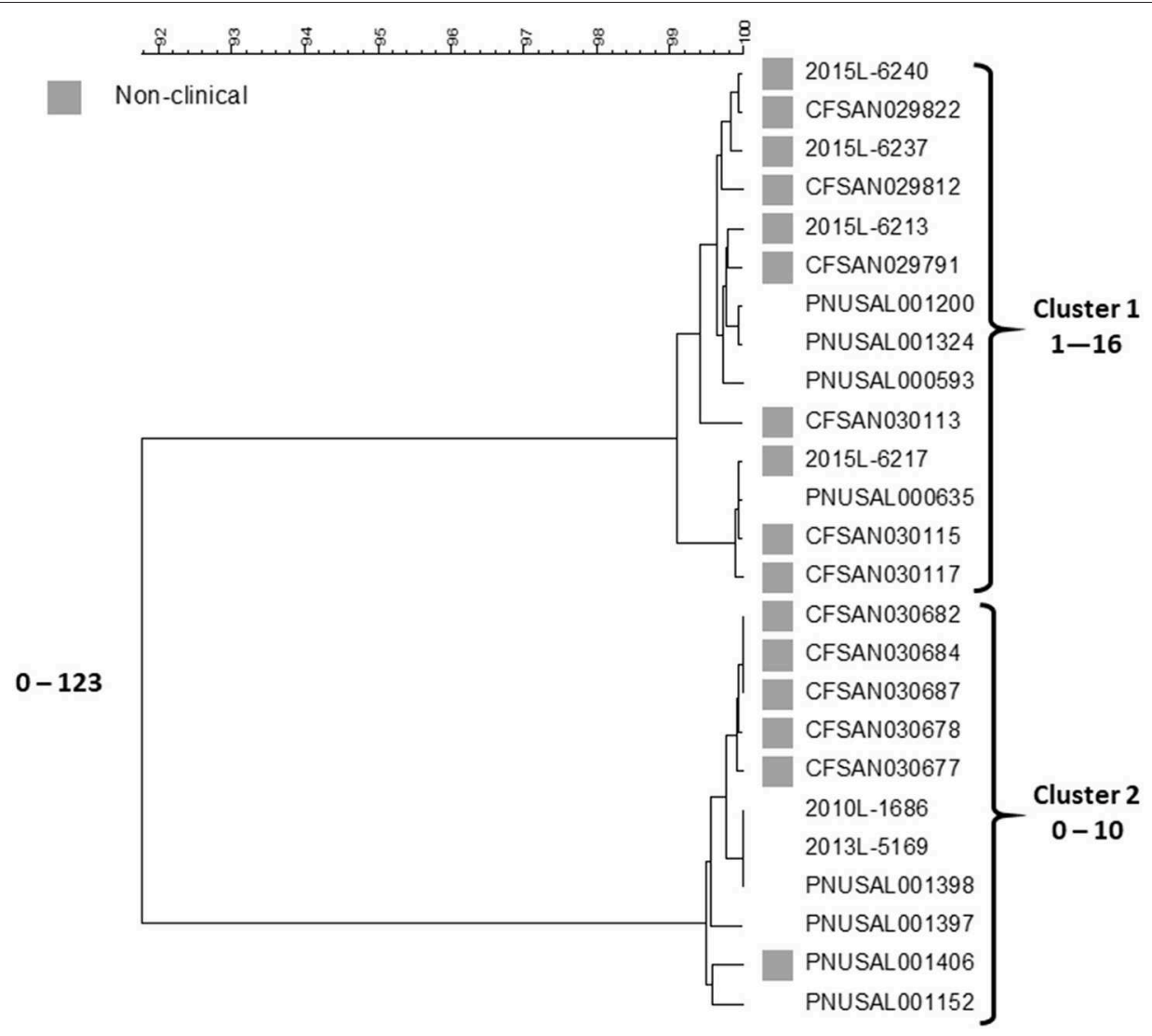

FIGURE 1 | cgMLST UPGMA tree of Lineage I isolate sequences the Listeria outbreak linked to ice cream. All clinical isolates and a representative sample of non-clinical product and production environment isolates are included in the tree. The range of allele differences are indicated at the branches of the tree and for clusters to the right of the tree.

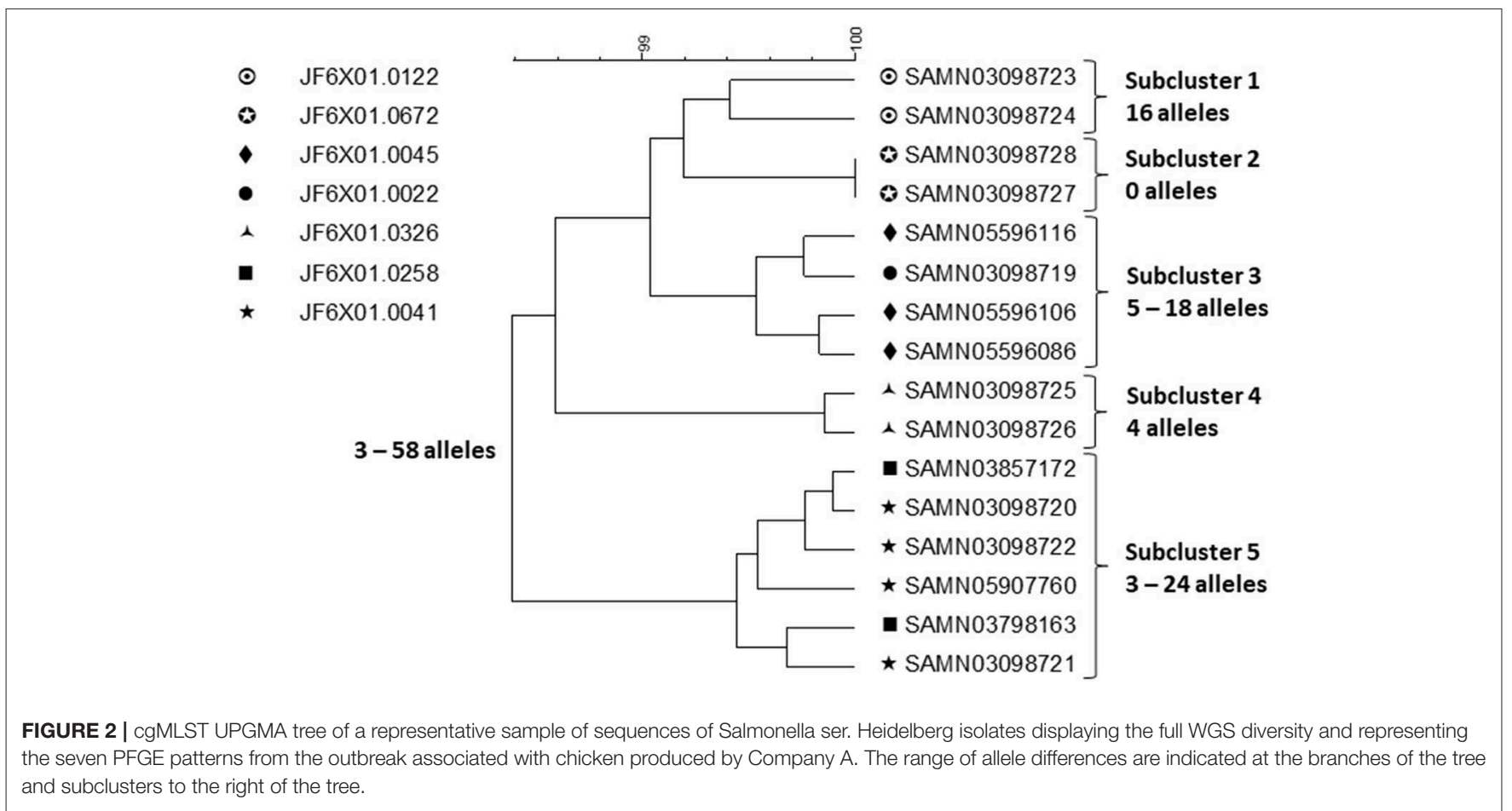

